\title{
Kozmetikte Yeni Trend: Spor Kozmetikleri
}

\author{
Murat ÜNALMIŞ ${ }^{*}$ \\ ${ }^{1}$ Iğdır Üniversitesi, Teknik Bilimler Meslek Yüksekokulu, Iğdır.
}

Derleme

Gönderi Tarihi: 02.12.2020
Kabul Tarihi: 13.12.2020
Online Yayın: 31.12.2020

\section{$\ddot{O}_{\mathbf{z}}$}

Bu çalışmada, spor kozmetiğinin terminolojiye kabul edilmesiyle birlikte, spor ile kozmetik arasında kurulan ilişki incelenmiştir. Spor kozmetiklerine ilişkin gerçekleştirilen araştırma ve literatür neticeleri taranarak sınıflandırılmıştır. Edinilen bulgularla spor kozmetikleri kavramı doğrulanmaya çalışılmıştır. Son yıllarda teknolojik gelişmeler birçok endüstri, ürün ve hizmetlerin üretilmesi ile sunulması noktasında büyük değişimlere sebep olmuştur. Bu değişimlerden biride kozmetik endüstrisi olmuş, sektör son yıllarda etkileyici bir hızla büyüme yaşamış bununla birlikte, spor pazarında da kendine büyük bir alan oluşturmuştur. Spor kozmetikleri kavramı, 1980'li yıllarda Spor Hekimleri ve Kozmetik Dernekleri tarafından tartışılmış ve uluslararası kongrelerde sunulmuştur. Bu bağlamda spor kozmetikleri; sporcuların egzersiz öncesi, egzersiz anı ve egzersiz sonrası her durumda ihtiyaçlarını karşılayan, yaşanılabilecek sakatlıkların önlenmesinde, yaşanmış olan sakatlıkların giderilmesinde kullanılmak üzere özel olarak geliştirilmiş ürünler olarak tanımlanmıştır. Spor kozmetiklerinin kullanımına, bilhassa estetik gerektiren bazı spor türlerinde (ritmik ve artistik cimnastik, buz pateni, su balesi, kule atlama, senkronize vb.) sıkça rastlanılmaktadır. Bunun birlikte sporcuda birtakım olguların (ihtiras, kararlılık, kuvvet, muvaffakiyet, zafer, amaç, üstün olmak, önderlik, heyecan, ekip, mutluluk, ümit, isteklendirme, kendine özgüven, güzellik ve cazibe) oluşturulması ve geliştirilmesi amacı ile de kozmetiklerden yararlanılmaktadır.

Ayrıca sporcularda ortaya çıkabilen cilt rahatsızlığı, cilt hastalıklarından korunma, enfeksiyonlar, mekanik yaralanma gibi durumlarda spor kozmetiklerinin tedavi edici özelliklerinden yararlanılmaktadır. Bu durum ise kozmetiklerin spor sektöründeki önemini her geçen gün artırmaktadır. Bu çalışmanın sonucunda, terminolojiye kabul edilen spor kozmetiklerinin spor ile kozmetik arasında bir bağ kurabileceği öngörülmektedir. Ayrıca sporcuların genel benlik algısı, özgüveni, iyi görünme hissi, konsantrasyonu ve performansı üzerinde olumlu bir etkiye sahip olabileceğini göstermektedir.

Anahtar Sözcükler: Spor kozmetikleri, Spor hijyeni, Kozmesötikler.

\section{New Trend in Cosmetics: Sports Cosmetics}

\begin{abstract}
In this study, with the acceptance of sports cosmetics to the terminology, the relationship between sports and cosmetics was examined and the research and literature findings on sports cosmetics were reviewed and classified. In the light of the obtained data, the concepts of sports cosmetics were introduced and the classifications were tried to be verified. In recent years, technological developments have caused great changes in the production and presentation of many industries, products and services. These changes have also taken place in the cosmetics industry and the sector has reached an impressive growth in recent years. With this growth, the sector has created a large area for itself in the sports market. The concept of sports cosmetics was discussed first by Sports Physicians and Cosmetic Associations in the 1980s and presented in international congresses. It was defined as specially developed products to meet the needs of athletes before, during and after their workouts in order to prevent injuries and recover from injuries. Sports cosmetics are widely used in sport branches such as rhythmic and artistic gymnastics, synchronized swimming, diving, fencing, high jumping and swimming, etc. On the other hand, it is used for the creation and development of some important concepts (passion, perseverance, strength, success, victory, goal, self-transcendence, leadership, excitement, team, joy, hope, motivation, self-confidence, beauty and charm) that are important for athletes. Additionally, the therapeutic properties of sports cosmetics are used in cases such as skin disorders, infections, mechanical injuries that may occur in athletes. These facts increase the importance of cosmetics in the sports sector day by day. As a result of this study, it is seen that sports cosmetics which are accepted to the terminology, have positive effects on athlete concentration and performance by establishing a link between sports and cosmetics.
\end{abstract}

Key Words: Sports cosmetics, Sports hygiene, Cosmeceuticals.

\footnotetext{
*Sorumlu Yazar: Öğrt. Gör. Murat ÜNALMIŞ, E-posta: murat.unalmis@igdir.edu.tr
} 


\section{GíRIŞ}

Kozmetik bilimi, insan organizmasını çevreleyen başta deri, tırnaklar, kıllar, saçlar, dudaklar olmak üzere dış genital organlar, dişler ve ağız mukozası gibi tüm bölgelerine tatbik edilmek üzere tasarlanmıştır. Bu bölgeleri temizlemek, koku vermek, görünümünü değiştirmek amacı ile hazırlanmış maddeleri inceleyen ve geliştiren bir bilim dalıdır (Kışlaoğlu, 2004; Sidle ve Decker, 2011). Kozmetik ürünler insanoğlunun tarih sahnesine çıkışından günümüze kadar gecen süreçte gündelik yaşamın önemli bir parçası olmuştur. Kazı bilimi araştırmaları neticesinde bulunan kozmetikler eski uygarlıklar hakkında birçok neticeyi de ortaya çıkarmıştır (Sungur, Şahne ve Yeğenoğlu, 2018).

Spor ve fiziksel aktivitenin tıbbi sağlık ve öznel refah için önemli olduğu ve bu nedenle bir tür sosyal fayda olarak işlev gördüğü iyi bilinmektedir (Seippel, 2006). Spor ve kozmetik arasındaki bağlantı ilk kez 1981'de Avusturya'nın St. Christoph şehrinde düzenlenen Uluslararası Spor Tıbbı Kongresi'nde tartışılmıştır. Devamında 1982'de Viyana'daki Dünya Spor Hekimliği Kongresi'nde konu yeniden gündeme getirilmiştir. Alman Kozmetik Derneği Kimyacıları tarafından ise Nisan 1982'de Batı Berlin'de tartışılmıştır (Greiter, 1985). Kozmetik ürünler, geçmişten günümüze çeşitli alanlarda teknolojik gelişmelerle değişim göstermiştir. Tarihin akışında toplumların yaşam kalitelerinin artması, kozmetikler içinde giderek artan bir ihtiyacı doğurmuştur. Parfümeriler, kozmetik uzmanları ve berberler gibi çeşitli meslek grupları çağlar boyunca gelişen kozmetik uygulamalarını üstlenmişler ve bu ürünlerin geliştirilmesine öncülük etmişlerdir (Blanco-Dávila, 2000; Çomoğlu, 2012). 21.yüzyılda giderek büyüyen sektörlerden biri olan kozmetik sektörü, pazar payını günden güne artırırken bu hızlı büyümesinin yanı sıra çeşitli alanlarda gösterdiği özel ihtiyaçlarla literatüre yeni terminolojiler kazandırmıştır. Bu bağlamda kozmetiğin en dikkat çekici terminolojisi "Spor Kozmetiğii” olmuştur.

Spor kozmetiği terminolojisi günümüzde, kozmetik sanayi tarafindan geniş bir yelpazede ticari kozmetik ürünler olarak kullanılmaktadır. Sporcuların egzersiz öncesi, egzersiz anı ve egzersiz sonrası birçok durumda yaşayabilecekleri sakatlıkların önlenmesi ile yaşanmış olan sakatlıkların giderilmesinde kozmetik ürünlerinin kullanımının etkin olduğu görülmektedir. Spor kozmetikleri, herhangi bir verimlilik kanıtı olmadan, sübjektif bir duygu sağlamak ve fiziksel performansı artırabilmek için geliştirilmiş, böylece sporcuların ihtiyaçlarına olumlu katkılar sağlamıştır (Clijsen, Barel ve Clarys, 2014). Bu kozmetik ürünleri kişisel bir olgu oluşturmanın yanı sıra sporcuların kendilerini daha özel ve fiziksel olarak daha aktif hissetmelerini, spor yaparken daha yüksek özgüvene sahip olmalarını sağlamak amacıyla da tercih edilmeye başlanmıştır. Farklı spor branşlarında çalışma yapan sporcuların yaptığı etkinliklere göre özel olarak tasarlanmış bu ürünler, kozmetik sektöründe hızla büyüyen ve önemini giderek artıran yeni bir alanı oluşturmaya başlamıştır. Spor kozmetikleri, özellikle estetikliğin ön plana çıktığı spor branşlarında (cimnastik, buz pateni vb.), sporcuların kendilerine özgüvenini artırmak, güzellik ve çekicilik algısını sağlayabilmek amacıyla da kullanılmaktadır. Yine fiziksel aktivite esnasında cildin korunması, 
fiziksel aktivite sonrasında ise sporcuların kişisel hijyenlerinin sağlanması bununla birlikte sıkça rastlanabilen dermatolojik hastalıkların tedavisinde spor kozmetikleri önemli bir yer tutmaktadır. Yapılan literatür taraması sonucunda seçilen konu ile ilgili araştırmaların çok sınırlı olduğu tespit edilmiştir. Var olan sınırlı sayıdaki çalışmalarda (Clijsen vd., 2014; Greiter, 1985) ise spor kozmetikleri kavramı ve sınıflandırılmasının yeteri kadar açıklığa kavuşmadığı düşünülmektedir. $\mathrm{Bu}$ durum ortaya konulan bu çalışmanın yapılmasının önem ve gerekliliğini göstermektedir. Spor kozmetiğinin terminolojiye kabul edilmesiyle birlikte bu çalışmanın amacı, spor ile kozmetiğin arasında kurulan ilişkinin belirlenmesi ve spor kozmetiklerinin sınıflandırılmasıdır.

\section{YÖNTEM}

Bu çalışmada spor kozmetikleri konusu üzerinde başlangıçtan Ağustos 2020'ye kadar Dünya'da ve Türkiye'de yazılmış makaleler incelenmiştir. PubMed, ISI Web of Science, Scopus ve tamamlayıcı Google Scholar araması dahil olmak üzere çeşitli veri tabanları üzerinde "Spor Kozmetikleri", "Spor ve Kozmetik" anahtar kelimeleri ile yapılan literatür taraması sonucunda 2 çalışmaya ulaşılmıştır. Bu çalışmaların ayrıntılı olarak incelenmesi yoluyla tematik bir derlemesinin yapılması amaçlanmıştır. Buradan hareketle bu derlemede 2 araştırma kapsamlı bir şekilde incelenmiştir. Kavramsal yapısı, güçlü ve zayıf yönleri açısından değerlendirilerek ve derlemede spor kozmetiklerinin tanımlanması ve sınıflandırılmasına yer verilmiştir.

\section{Spor Kozmetiklerin Sinıflandırılması}

Spor kozmetikleri, cilt üzerinde bıraktı̆̆ potansiyel ve biyolojik etkiler bakımından beş ana başlıkta sınıflandırılabilir.

\section{1-Estetik Spor Kozmetikleri,}

2-Cilt Koruyucu Spor Kozmetikleri,

3-Tedavi Edici Kozmesötikler, 4- Uyarıcı Spor Kozmetikler

5-Hijyenik Spor Kozmetikleri

\section{Estetik Spor Kozmetikler}

Spor ve fiziksel aktivitenin sağlık, öznel iyi oluş, imaj, güç ve zindelik gibi duygularımız üzerinde olumlu bir etkisi vardır. Sporda "beden ve görünüm" oldukça önemlidir. Genel benlik saygısı açısından kadınların erkeklerden daha fazla beden imajı hassasiyeti bulunmaktadır. $\mathrm{Bu}$ hassasiyette yaş ve cinsiyet arasındaki etkileşim önemlidir. Sosyal araştırmacılarla ilgili farklı, ancak ilişkili bir soru, sporun fiziksel aktivite ve sırasıyla tıbbi sağlık ve 'öznel iyi oluş' arasındaki varsayılan (olumlu) ilişkiler aracıllğıyla bir sosyal fayda olarak nasıl işlediğidir Modern toplumlarda sağlık, güzellik ve gençliği koruma arzusu büyük önem taşımaktadır (Seippel, 2006). İnsanlar yaşlanmanın etkilerini geciktirmek veya en aza indirgemek için bu amaçla tasarlanmış kozmetik ürünlerine yönelim göstermektedirler (Manela-Azulay ve Bagatin, 2009). Bazı spor 
filozofları, bazı spor unsurlarının spor deneyimini estetik bir deneyim haline getirme yeteneklerini zaten düşünmüş ve tartışmışlardır (Lacerda, 2002). Bazıları için bu estetik unsurlar, sporcuları sporun bağlamlarının bir parçası olmaya yönlendiren ana ve derin motivasyondur (Wertz, 1983; Witt, 1989). Sporda güzellik yönü, özellikle televizyon yayınlarının ortaya çıkışı ile önem kazanmıştır. Dünya şampiyonaları ve olimpiyat oyunları için hazırlanan özel kozmetik hizmetleri güzelliğe olan ilgiyi resmi hale getirmiştir. Bu sayede çekicilik ve güzellik olgusu sporcular ve bazı branşlar için önem kazanmıştır (Greiter, 1981). Cimnastik, buz pateni ve senkronize yüzme gibi estetik gerektiren branşlarda iyi görünümün yarışmanın bir parçası olduğu izlenimini sağlamak için kullanılmıştır. Sporcunun kendine olan güvenini artırmak, hakemler komitesinin değerlendirmesinde katkı sağlayacak estetik görünüşü tamamlamak için tasarlanmışlardır. Kadın sporcuların mümkün olduğunca çekici olmaları, renkli kozmetik kullanımına giderek daha fazla ilgi göstermelerini sağlamıştır. Sporcuların mutlu ve çekici kişilikleri, medya ve sponsorların ilgisini çekmeleriyle medya tanıtımlarının kariyerleri üzerindeki etkilerini de beraberinde getirmektedir. Bugün şirketler kendi kozmetik serilerini; renklerle, spor malzemelerindeki kıyafetlerin çizgi, görünümü ile destekleyerek ortaya çıkarmaktadır. Bu spor kozmetikleri, su geçirmez, tere dayanıklı makyaj ve deodorant kokuları gibi bireysel sporcunun ihtiyaçlarına göre uyarlanmaktadır (Clijsen vd., 2014). Bütün bunlar, kozmetik kullanımı ile kendine güven arasındaki ilişkiyi, öz-imge ve güvencenin yanı sıra sosyal kabul ilişkisini de ortaya çıkarmaktadır. Çekiciliğin mutlulukla ilişkili olduğu düşünüldügünde sporcuların, iyi görünüşü geliştiren ve kişiliği vurgulayan spor kozmetikleriyle sporda hedeflerine ulaşmalarına yardımcı olabileceğini düşünülmektedir (Cash ve Walker, 1982).

\section{Cilt Koruyucu Spor Kozmetikler}

Deri, çeşitli spor dallarında sıklıkla etkilenen bir organdır. Sporla ilişkili dermatozlar, enfeksiyonlar, inflamatuar durumlar, travmatik lezyonlar, çevresel faktörlere bazı lezyonlar ve neoplazmlar şeklinde sıralanabilir (Greiter, 1984). Birçok aktivitede spor cilt yüzeyine stres uygular. Uygulanan aktiviteye bağlı olmakla birlikte fiziksel egzersiz sırasında, bir sporcunun derisi genellikle zorlu çevre koşullarına maruz kalmaktadır. Kayak, dağcılık, bisiklet veya triatlon gibi açık hava sporları yapan sporcular, yüksek güneşe maruz kalan antrenman ve müsabaka programları nedeniyle ve alp sporlarında yüksekliğe bağlı ultraviyole (UV) radyasyonunun artması ve kar ve buzla kaplı yüzeylerden yansıma nedeniyle önemli miktarda UV dozu alırlar (Moehrle, 2008). Çok merkezli güney Avrupa çalışması Helios II, yüzme, sörf, tekne gezintisi ve yelken gibi yoğun ultraviyole radyasyona maruz kalan su sporlarına katılan sporcuların bazal hücreli karsinom (BCC) gelişimi için yüksek risk altında olduğunu göstermiştir (Rosso vd., 1996). Kozmetiklerin koruma ve bakımda önemli fonksiyonlarının bulunduğu bilinmektedir. Cildi korumak için sporcunun gereksinimleri doğrultusunda kozmetik endüstrisi koruyucu cilt bakım ürünleri ve özel koruyucular geliştirmiştir. Sporda etkili cilt koruması özel bir önem taşır. (Greiter, 1981). Nolting (1982), sporun önemli bir parçasını hijyen olarak tanımlamıştır. Spor performansında çevre ve giysinin (özellikle giyilen kumaş türü) cilt ve enfeksiyon olasıllğı üzerine büyük bir etkiye sahiptir. Yakın temas gerektiren sporlarla uğraşanlarda temel sağlık sorunlarından biri de cilt 
enfeksiyonlarıdır. Bilhassa güreşte, sporcular güreşirken ciltler arasında meydana gelen temas ile sporcular arasında cilt enfeksiyonları kolaylıkla bulaşabilmektedir. Bundan dolayı güreşçilerde cilt enfeksiyonları çok yaygın görülür (Kaynar vd., 2017; Kordi, Ziaee, Rostami,Wallace, 2012). Sporcularda sik görülen dermatolojik problemler verrüler, M. kontagiosum, Herpes simpleks enfeksiyonları ve fungal enfeksiyonlardır. Tine pedis ve Tinea cruris gibi fungal enfeksiyonlar şiddetli pruritusa yol açmaları nedeniyle sporcunun konsantrasyonunu etkileyebilmektedir (Hareke ve Roseeuw, 1999; Mantar, 2001). Doğru kozmetikler hidro-iyon konsantrasyonu, ph değeri, nem içeriği, yağ asitleri ve mikroorganizmalar bakımından cildin doğal dengesini korumaya yardımcı olabilmektedir. Kozmetiklerin formülasyonu ve kıvamı çeşitli spor disiplinlerinin gereksinimlerini karşılayabilmektedir. Sudaki yağ ve su yağ emülsiyonları, jeller gibi bazı ürünler bireysel sporcuların özel ihtiyaçlara göre seçilmesi gerekliliğini ortaya koymaktadır (Groll, 1984).

\section{Tedavi Edici Kozmesötikler}

Kozmesötik terimi, 1984 yılında dermatolog Dr. Albert Kligman tarafından kavramlaştırılmıştır. Kozmetik ve farmasötik kelimelerinin bir kombinasyonundan türetilmiştir. Kozmesotikler hem kozmetik hem de terapötik (tıbbi veya ilaç benzeri) etkilere sahip cilt sağlığı ve güzelliği üzerinde yararlı bir etkiye sahip olmaları için amaçlanan ürünlerdir. Kozmetikler gibi, topikal olarak kremler veya losyonlar olarak uygulanırlar, ancak cilt hücresi fonksiyonu üzerinde etkisi olan aktif bileşenleri içerirler. Bazı durumlarda, eylemleri cilt yüzeyi ile sınırlı iken (eksfoliyanlar gibi), diğerleri de normal cilt fonksiyonlarını artırarak veya sınırlandırarak daha derin seviyelere nüfuz edebilmektedirler. Kozmesötikler reçetesiz olarak ve genellikle cilt tonunu, dokusunu, pigmentasyonunu ve ince çizgileri iyileştirmeye yardımcı olmak için düzenli bir cilt bakım rejiminin bir parçası olarak kullanılmaktadırlar. Kozmesötikler; canlı doku üzerinde farmasötik bir etkiye sahip olmadan biyolojik fayda sağlayan kozmetik ürünlerdir. Kozmesötikler sporla ilişkili dermatolojik bozuklukların tedavilerde etkilidir ve reçeteli ilaçlar olarak yararlı bir yardımcı olabilirler (Hunt, 2020).

\section{Uyarıcı Spor Kozmetikler}

Uyarıcı ürünler özellikle hyper-aemising veya soğutma kapasitesi olanlar için sıklıkla sporcu ya da spor yapan bireylerin vücutlarının fiziksel hazırlık performansını artırmak için kullanılmaktadır. Leite ve Ribeiro (2010) yapmış olduğu bir çalışmada bir soğutma sıvısının geleneksel kriyoterapiye karşı terapötik etkinliğini değerlendirmişler ve çalışmalarında katılımcılara iki kriyoterapi yöntemi (oda sıcaklığında islak havluda kırılmış buz ve sıvı buz) uygulamışlardır. Hohenauer, Clijsen, Cabri ve Clarys (2009) tarafından yapılan bir çalışmada, sıvı buz uygulamasına kıyasla kırılan buz uygulamasının daha düşük cilt yüzey sıcaklığına neden olduğu sonucuna ulaşılmıştır. Ayrıca spor kozmetiklerinde kullanılan yasemin yağının, kanda oksijen doygunluğunda, solunum hızında, sistolik ve diyastolik kan basıncında önemli uyarıcı etkilerinin olduğu ifade edilmiştir (Hongratanaworakit, 2010). 


\section{Hijyenik Spor Kozmetikler}

Takım şeklinde yapılan spor türlerine katılmanın sporcu üzerinde olumlu etkileri olabileceği gibi aynı zamanda sporcunun çeşitli bulaşıcı hastalıklara maruz kalması riskini de oluşturmaktadır. Enfeksiyon için başlıca risk faktörleri arasında, aktif cilt enfeksiyonları olan sporcularla cilt teması, çevresel maruziyetler, fiziksel travma, ekipman paylaşımı ve kontamine nesneler (fomitlerle) yer alır. Takım sporlarına özgü yakın temas ve ergenlikle ilişkili psikososyal faktörler ek risklerdir. Temel hijyen davranışları, sporla ilişkili enfeksiyonların tanınmasına, teşhisine, tedavisine ve önleyici müdahalelerin uygulanmasına bağlıdır (Gomez-Lopez vd., 2008). Fiziksel aktiviteden sonra, yeterli kişisel hijyen vücudun sağlıklı kalmasında hayati bir önem taşımaktadır. Yapılan her egzersizden sonra duş alma ve temizlik amaçlı kozmetik ürünü kullanımı gereklidir. Böylece $\mathrm{Ph}$ değeri bakımından nem içeriği ve temiz bir cilt kapasitesi sağlanmış, cildin doğal dengesi desteklenmiş olur (Clijsen vd., 2014).

\section{SONUÇ VE ÖNERILER}

$\mathrm{Bu}$ çalışmanın amac1; kozmetik endüstrisi tarafından çok çeşitli kozmetik ürünlerin ticarileştirilmesi için kullanılan "Spor kozmetiğì" terminolojisi ile ilgili literatürü araştırmaktır. Ayrıca kozmetiklerin spordaki rolü, psiko fiziksel uyarım aracı, vücudu sağlıklı tutmak için değerli bir önleyici tedbir ve spor aktivitelerinin hedeflerine ulaşmak için önemli bir yardım olarak tanımlayabilmek için bir çalışma yapmaktır. Fakat literatürde spor kozmetiği terminolojisini kullanan oldukça sınırlı sayıda çalışmanın mevcut olduğu görülmüştür (Clijsen vd., 2014; Greiter, 1985). Bu çalışma, literatürde mevcut olan bu boşluğu doldurması açısından önem arz etmektedir. $\mathrm{Bu}$ çalışma da örneğin bir maraton koşucusunun, binici bir kadının, bir triatletin veya üst düzey bir sporcunun ihtiyaç duyduğu gerçek performans gösteren kozmetik ürünlerini tam olarak tanımadığı veya özelleştirilmiş ürünlerin çok az sayıda ve bazı ülkelerde geliştirildiği tespit edilmektedir.

Spor aktivitelerinde, sporcuların gereksinimlerini karşılayacak özel tasarlanmış kozmetik ürünleri geliştirmenin gerekliliği öngörülmektedir. Aktif olarak spor yapan tüm bireylerin antrenman ya da müsabakalar da cilt bakım ve korumasına ihtiyaç duyduğu düşünülmektedir. Sporcuların kendine olan güveni ve doğal güzelliğini arttırmakla birlikte sadece iyi görünmekle kalmayıp aynı zamanda sporcunun kendisini harika hissetmesine yardımcı olan ürünlerin geliştirilmesine ihtiyaç bulunmaktadır.

"Spor kozmetik" terminolojisi, kozmetik endüstrisi tarafından çok çeşitli kozmetik ürünleri ticarileştirmek için kullanılmaktadır. Bazıları sporda kullanım için özel olarak geliştirilmiş ve sporcuların ihtiyaçlarına iyi uyarlanmıştır (Clijsen vd., 2014). "Spor ile kozmetiğin arasında kurulan doğal bağlantının, sporun ve spor yapan insanların ihtiyaçlarına göre tasarlanan bu ürünlerin gerekliği şart mı?" sorusu tartışılması ve üzerine daha çok çalışma yapılması gereken konular arasındadır. Sporcunun kendine özgüveni, güzellik ve çekicilik algısı, spor esnasında cildin korunması, dermatolojik hastalıkların tedavisinin sağlanması, spora teşvik etmek için 
vücudun fiziksel performansının artırılması ve fiziksel aktivite sonrasında sporcuların kişisel hijyenlerinin sağlanması önemli konulardandır. Spor kozmetikleri; sporcuların hedeflerine ulaşmalarına yardım eden, her türlü hazırlık, koruma ve fiziksel iyileşme ihtiyaçlarını karşılayan, sporculara dinamik, yenilikçi ve üstün ürünler oluşturmayı hedefleyen bir sektör haline geleceği düşünülmektedir. Sporcuların branşlarına bakılmaksızın, diğer ergojenik yardımcılarla birlikte uygulanabilir ve değerlendirilebilir. Spor kozmetiklerinin oyuncular üzerindeki etkisini daha iyi anlamak için bu tür araştırmaların bir sonraki çalışmalarda yapılması öngörülmektedir. Dünyada spor kozmetikleri başlığı adı altında tasarlanan tüm ürün kombinasyonları egzersiz ve sporda kullanılan en yeni trend ürünler olabilmektedir. Sporda, masaj başlama yağları, güneş koruyucu yağlar, geri toparlanmada etkili yağlar, cilt koruma kremleri, spor makyajı gibi ürünlerin ergojenik bir etkiye sahip olduğu ve dolayısıyla fiziksel performansın iyileştirilmesine yardımcı olabileceği düşünülmektedir.

Sonuç olarak bu ürünlerin egzersiz performansı üzerindeki etkileri ve bu etkilerin eş zamanlı olarak spor performansı ile ilişkili olup olmadığını belirleyebilmek için daha fazla çalışmaya ihtiyaç duyulmaktadır. Bu bağlamda araştırmacıların söz konusu konuları çalışmaları için teşvik edilmesi gerekmektedir. Bu derlemenin spor kozmetikleriyle ilgili bundan sonra yapilacak olan çalışmalara 1şık tutacağı düşünülmekte olup, sporcularda kullanılan kozmetiklerin etkilerini araştıran daha detaylı bir çalışmanın temelini oluşturabilir. 
Ünalmış, M. (2020). Kozmetikte yeni trend: Spor kozmetikleri. Avrasya Spor Bilimleri ve Eğitim Dergisi, 2(2), 135146.

\section{KAYNAKLAR}

Blanco-Dávila, F. (2000). Beauty and the body: The origins of cosmetics. Plastic and reconstructive surgery, 105(3), 1196-1204. DOI: 10.1097/00006534-200003000-00058.

Cash, T.F. \& Walker Cash, D. (1982). Women's use of cosmetics: Psychosocial correlates and consequences. International Journal of Cosmetic Science, 4: 1-13. https://doi.org/10.1111/j.1467-2494.1982.tb00295.x.

Clijsen, R., Barel, A. O. \& Clarys, P. (2014). Use of Cosmetics in Sports. Erişim tarihi; 06.12.2020, https://www.researchgate.net/profile/Ron_Clijsen/publication/263397952_The_Use_of_Cosmetics_in_Spo rt/links/54c7a8580cf238bb7d0af5be/The-Use-of-Cosmetics-in-Sport.pdf.

Çomoğlu, T. (2012). Kozmetikler. Marmara Pharmaceutical Journal, 16(1), 1-8. DOI: 10.12991/201216414.

Greiter, F. (1981). Kosmetik und Spon. Osterreich Journal fur Sponmedizin, 2, 9-15.

Greiter, F. (1985). Sports and cosmetics. Sports Medicine, 2(4), 248-253. DOI: 10.2165/00007256-198502040-00002.

Greiter. F. (1984). Moderne Cosmetic. In press: 67-71; 310-317; 211- 214; 217-218.

Groll, D. (1984). Kosmetiktage Karlsruhe zu Gast in Berlin. Parfiimerie und Kosmetik, 62 (Suppl. 8): 246.

Gomez-Lopez, A., Alastruey-Izquierdo, A., Rodriguez, D., Almirante, B., Pahissa, A., Rodriguez-Tudela, J. L. \& Cuenca-Estrella, M. (2008). Prevalence and susceptibility profile of Candida metapsilosis and Candida orthopsilosis: results from population-based surveillance of candidemia in Spain. Antimicrobial agents and chemotherapy, 52(4), 1506-1509. DOI:10.1128/AAC.01595-07.

Hareke, E. \& Roseeuw, D. (1999). The scope of onycomycosis: epidemiyology and clinical features. Int J Dermatol, 38(2), 7-12. DOI: 10.1046/j.1365-4362.1999.00015.x.

Hohenauer, E., Clijsen, R., Cabri, J. \& Clarys, P. (2009). Effects of different local cooling applications on the endurance capacity during cycling. 14th Annual Congress of the European College of Sport Science Book of Abstracts (ss.321). Oslo/Norway.

Hongratanaworakit, T. (2010). Stimulating effect of aromatherapy massage with jasmine oil. Natural product communications, 5(1), 157-162. https://doi.org/10.1177/1934578X1000500136.

Hunt, M. (2020). Kozmesötikler. Erişim tarihi; 20.02.2020, https://www.dermcoll.edu.au/atoz/cosmeceuticals/.

Kaynar, Ö., Engin, R. İ., Dağdeviren, F., Yılmaz, M., Özkan, B. \& Öztürk, S. (2017). Türk güreşçilerde deri enfeksiyonları sıklığının araştırılması. Turkderm, 51(3), 84. DOI: 10.4274/turkderm.81231.

Kışlalığlu, S. (2004). Kozmetoloji Bilimi. In: Kozmetik Bilimi. (Editors: Yazan, Y.,). İstanbul: Nobel Tıp Kitabevi, $3-9$.

Kordi, R., Ziaee, V., Rostami, M. \& Wallace, W. A. (2012). Sports injuries and health problems among wrestlers in Tehran. JPMA-Journal of the Pakistan Medical Association, 62(3), 204-208.

Lacerda, T.O. (2002). Elementos para a construc, ã de uma Estética do Desporto. Not Published Doctoral Dissertation, Faculty of Sports of the University of Porto, Porto. 
Ünalmış, M. (2020). Kozmetikte yeni trend: Spor kozmetikleri. Avrasya Spor Bilimleri ve Eğitim Dergisi, 2(2), 135146.

Leite, M. \& Ribeiro, F. (2010). Liquid IceTM fails to cool the skin surface as effectively as crushed ice in a wet towel. Physiotherapy theory and practice, 26(6), 393-398. https://doi.org/10.3109/09593980903229240.

Mantar, F. Y. (2001). Deri Hastalıkları ve Frengi Arşivi, Türkderm, 35(4), 1-5.

Manela-Azulay, M., \& Bagatin, E. (2009). Cosmeceuticals vitamins. Clinics in dermatology, 27(5), 469-474. https://doi.org/10.1016/j.clindermatol.2009.05.010.

Moehrle, M. (2008). Outdoor sports and skin cancer. Clinics in dermatology, 26(1), 12-15. DOI: 10.1016/j.clindermatol.2007.10.001.

Rosso, S., Zanetti, R., Martinez, C., Tormo, M. J., Schraub, S., Sancho-Garnier, H., ... \& Laurent, R. (1996). The multicentre south European study'Helios'. II: Different sun exposure patterns in the aetiology of basal cell and squamous cell carcinomas of the skin. British journal of cancer, 73(11), 14471454.DOI: 10.1038/bjc.1996.275.

Sidle, D. M. \& Decker, J. R. (2011). Use of makeup, hairstyles, glasses, and prosthetics as adjuncts to scar camouflage. Facial Plastic Surgery Clinics, 19(3), 481-489. DOI: 10.1016/j.fsc.2011.06.004.

Seippel, Ø. (2006). The meanings of sport: fun, health, beauty or community?. Sport in Society, 9(1), 51-70. DOI: $10.1080 / 17430430500355790$.

Sungur, S. A., Şahne, B. S. ve Yeğenoğlu, S. (2018). Kozmetik ürünlerin tarihçesi, ürün tanıtımlarının yasal durumu ve tüketici davranışı açısından değerlendirilmesi. Mersin Üniversitesi Tlp Fakültesi Lokman Hekim Tip Tarihi ve Folklorik Tip Dergisi, 8(3), 191-197. DOI: 10.31020/mutftd.432259.

Wertz, S. K. (1983). Context and intention in sport and art. Southwest Philosophical Studies San Marcos, Tex, 8(3), 145-147.

Witt, G. (1989). The world of sport-A world of aesthetic values. Sport Science Review, 12, 10-15. 


\section{EXTENDED ENGLISH SUMMARY}

\section{New Trend in Cosmetics: Sports Cosmetics}

Introduction: The link between sports and cosmetics was first established in 1981 at the St Christoph, Austria International Congress of Sports Medicine. This issue was brought to the agenda at the sports medicine world congress in Vienna in 1982 and was discussed by the German Cosmetic Association Chemists in West Berlin in April 1982 (Greiter, 1985). The cosmetics sector, one of the growing sectors in the 21 st century, has increased its market share day by day and has brought new terminologies to the literature with its special needs in various fields as well as its rapid growth. In this context, the most striking terminology of cosmetics has been "Sports Cosmetics". Sports cosmetics terminology is currently used by the cosmetic industry in a wide range of commercial cosmetic products. It is seen that the use of cosmetic products is effective in eliminating the injuries experienced by the athletes before, during and after exercise in many cases. Sports cosmetics were developed to provide a subjective feeling and increase physical performance without any evidence of efficiency, thus making positive contributions to the needs of athletes (Clijsen et al, 2014). These products, specially designed according to the activities of athletes working in different sports branches, have started to create a new field that is growing rapidly and increasing its importance in the cosmetics sector. Sports cosmetics are also used in sports branches where aesthetics are at the forefront (gymnastics, ice skating, etc.) to increase the self-confidence of the athletes and to provide the perception of beauty and attractiveness. Again, protecting the skin during physical activity and providing personal hygiene of athletes after physical activity, sports cosmetics have an important place in the treatment of dermatological diseases that can be encountered frequently. As a result of the literature review, it was determined that the researches on the selected subject are very limited. In the limited number of studies available (Clijsen et al, 2014; Greiter, 1985), it is thought that the concept and classification of sports cosmetics have not been adequately clarified. This situation shows the importance and necessity of carrying out this study. In this study, the results of the research and literature on sports cosmetics were classified and the relationship established between sports and cosmetics with the acceptance of sports cosmetics as terminology was examined. At the same time, the cosmetics industry, which grows and develops very rapidly with technological developments, has been tried to be classified by introducing the concept of sports cosmetics, a phenomenon that is designed and created according to the needs of sports and athletes, with the idea of opening a commercial field.

\section{Classification of Sports Cosmetics}

Aesthetic Sports Cosmetics: Sport and physical activity have a positive effect on our emotions such as health, subjective well-being, image, strength, and well-being. "Body and appearance" is very important in sports. The beauty aspect in sports has gained importance especially with the advent of television broadcasts. Special cosmetic services prepared for the World Championships and Olympic Games have made the interest in beauty official. In this way, the phenomenon of charm and beauty has gained importance for athletes and some branches (Greiter, 1981). Today 
companies have their own cosmetic lines; colors, the line of the clothes in sports equipment, supported by the appearance. These sports cosmetics are tailored to the needs of the individual athlete, such as waterproof, sweat-resistant make-up and deodorant fragrances (Clijsen et al, 2014). All these reveal the relationship between cosmetic use and self-confidence, the relationship between self-image and assurance, as well as social acceptance. Considering that attractiveness is related to happiness, it is thought that it can help athletes achieve their goals in sports with sports cosmetics that improve good looks and emphasize personality (Cash ve Walker, 1982).

Skin Protective Sports Cosmetics: The skin is an organ that is frequently affected in various sports. Sports-related dermatoses can be listed as infections, inflammatory conditions, traumatic lesions, some lesions and neoplasms to environmental factors (Greiter, 1984). In many activities, sports apply stress to the skin surface. Depending on the activity applied, an athlete's skin is often exposed to harsh environmental conditions during physical exercise. Athletes engaged in outdoor sports such as skiing, mountaineering, cycling or triathlon receive significant UV doses due to training and competition programs with high sun exposure, and altitude-related increased UV radiation in alpine sports and reflection from snow and ice-covered surfaces (Moehrle, 2008). In line with the needs of the athlete, the cosmetic industry has developed protective skin care products and special preservatives to protect the skin. Effective skin protection is of particular importance in sports. Lesions such as protection against sunburn, cold air, cold water, insect bites, abrasions or blisters against application are increasingly important for effective cosmetics. (Greiter, 1981). The formulation and consistency of cosmetics can meet the needs of various sports disciplines. Some products such as oil and water oil emulsions and gels in water reveal the necessity of choosing individual athletes according to special needs (Groll, 1984).

Therapeutic Cosmeceuticals: The term cosmeceutical was introduced by dermatologist Dr. by Albert Kligman. Derived from a combination of the words cosmetics and pharmaceuticals like cosmetics, they are applied topically as creams or lotions, but contain active ingredients that have an effect on skin cell function Cosmeceuticals are used over-the-counter and are often used as part of a regular skincare regimen to help improve skin tone, texture, pigmentation, and fine lines. Cosmeceuticals are cosmetic products that provide biological benefits without having a pharmaceutical effect on living tissue. Cosmeceuticals are effective in treating sports-related dermatological disorders and can be a useful aid as prescription drugs (Hunt, 2020).

Stimulating Sports Cosmetics: Stimulant products are often used to increase the physical preparation performance of the bodies of athletes or individuals who do sports, especially for those who have hyper-aemising or cooling capacity. In addition, it has been stated that jasmine oil used in sports cosmetics has important stimulating effects on oxygen saturation in the blood, respiratory rate, systolic and diastolic blood pressure (Hongratanaworakit, 2010). 
Hygienic Sports Cosmetics: Participating in sports that are done in a team form can have positive effects on the athlete, as well as the risk of exposure to various infectious diseases. Major risk factors for infection include skin contact with athletes with active skin infections, environmental exposures, physical trauma, equipment sharing, and contaminated objects (with fomites). Close contact specific to team sports and psychosocial factors associated with adolescence are additional risks. It depends on the recognition, diagnosis, treatment and implementation of preventive interventions of basic hygiene behaviors, sports-related infections (Gomez et al, 2008). After physical activity, adequate personal hygiene is vital to keeping the body healthy. It is necessary to use cosmetic products for showering and cleaning after each exercise (Clijsen et al, 2014).

Conclusion and Suggestions: The aim of this study is; To research the literature on the terminology of "Sports cosmetics" used by the cosmetics industry to commercialize a wide variety of cosmetic products. In addition, the role of cosmetics in sports is to conduct a study to define it as a tool of psycho-physical stimulation, a valuable preventive measure to keep the body healthy, and an important aid in achieving the goals of sports activities. However, it has been observed that there are quite a limited number of studies using the terminology of sports cosmetics in the literature (Greiter, 1985; Clijsen 2014). This study is important in terms of filling this gap in the literature. It is anticipated that different high-performance cosmetic products specially designed to meet the sports activities and the needs of the athletes should be brought. It is anticipated that all individuals who do sports actively need make-up, skin care and protection, which should be created either in competitions, in the gym or on the dance floor, considering all kinds of sports exercises. It is believed that there is a need to develop products that not only look good, but also help the athlete to feel great, while increasing self-confidence and enhancing natural beauty in athletes. We propose to create a sector with all stakeholders that accompanies athletes to achieve their goals and creates dynamic and innovative superior products that meet the needs of athletes for preparation, protection and physical recovery. Sports cosmetics can be a useful and ethical tool for athletes to achieve their goals in sports. It can be applied and evaluated in conjunction with other ergogenic aids, regardless of the athlete's branch. In order to better understand the effect of sports cosmetics on actors, such research is envisaged to be carried out in the next studies. As a result, more studies are needed to determine the effects of these products on exercise performance and whether these effects are simultaneously related to sports performance. In this context, researchers should be encouraged to study these issues. It is thought that this review will shed light on the future studies on sports cosmetics and may form the basis of a more detailed study investigating the effects of cosmetics used in athletes.

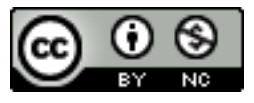

Except where otherwise noted, this paper is licensed under a Creative Commons Attribution 4.0 International license. 